\section{ПРОБЛЕМЫ НАУЧНОГО ИЗУЧЕНИЯ И ПРАКТИЧЕСКОГО ОСВОЕНИЯ ТУВИНСКОЙ МУЗЫКИ (НА ПРИМЕРЕ ТУВИНСКОГО ИНСТРУМЕНТАЛЬНОГО ИСКУССТВА)}

\author{
Валентина Ю. Сузукей \\ Тувинский институт гуманитарных \\ и прикладных социально- \\ экономических исследований, \\ Россия
}

В ХХ в. тувинская музыкальная культура пережила глубинные потрясения, трансформации. Сегодня есть острая необходимость переосмысления достижений и потерь. Цель работы - попытка рассмотрения некоторых базовых параметров тувинской музыкальной культуры, сохраняющих системную целостность в звуковой структуре. Актуальность темы продиктована существующими концептуальными расхождениями между музыкальной практикой и научным ее освоением.

В советское время унификация культуры на всей территории СССР была ориентирована исключительно на европейскую модель развития музыкального творчества без учета специфики этнических культурных практик. В настоящее время уменьшается число носителей традиционной культуры устно-слухового типа, увеличивается число выпускников музыкальных школ, училищ, консерваторий и университетов, академий культуры и искусств, воспитанных не на традиционных цеен-

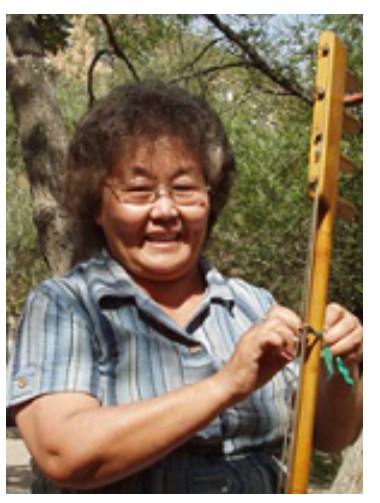

In the 20th century, Tuvan music culture has undergone dramatic upheaval and a number of transformations. Today we face an acute need to rethink the achievements and losses incurred over that period of time. The objective of this article is to reconsider some basic parameters of Tuvan music culture that are responsible for preserving the integrity of its sound structure. The relevance of the topic is due to a current conceptual rift between the musical practices and their scholarly interpretations.

In the Soviet period, culture throughout the entire USSR was solely driven by the European model of musical development with no reliance on practices typical for ethnical cultures. We are currently witnessing a decline in the numbers of those representing oral and audial traditional culture,

Сузукей Валентина Юрьевна - кандидат искусствоведения, доктор культурологии, главный научный сотрудник сектора культуры Тувинского института гуманитарных и прикладных социально-экономических исследований. Адрес: 667000, Россия, г. Кызыл, ул. Кочетова, д. 4. Тел.: +7 (394-22) 2-39-36. Эл. адрес: vsuzukei@mail.ru

Suzukey Valentina Yur'evna, Candidate of Arts, Doctor of Culturology, Chief Research Fellow, Sector of Culture, Tuvan Institute of Humanities and Applied Social and Economic Research. Postal address: 4 Kochetov St., Kyzyl, Republic of Tuva, Russian Federation 667000. Tel.: +7 (394-22) 2-39-36. E-mail: vsuzukei@mail.ru 
ностных ориентирах. В тувинскую музыкальную практику активно внедряется академическая терминология и привносятся не свойственные критерии оценок и термины. Но тувинская культура была принципиально устной и выработала свою систему звукового строя, механизмы и методы бесписьменной передачи знаний. Но эти народные методы до сих пор остаются малоизученными.

Автор утверждает, что система организации тувинской инструментальной музыки специфична и выступает основой, которая придает необычность звучанию музыкальных инструментов и хоомея (горлового пения). Характерный тембр и неповторимый колорит их звучания обеспечивается своеобразной системой бурдонно-обертоновых звуковых соотношений.

Музыка является творением, предназначенным для слухового восприятия. А музыковеды, в основном российские, продолжают анализировать нотированные варианты записанных ими исполнений народной инструментальной музыки и хоомея. Такой подход ограничивает всю панораму традиционной инструментальной музыки.

Положительно оценивается то, что современные тувинские музыканты владеют нотной грамотой, и приобщаются к шедеврам мировой музыкальной классики. Но, утверждает автор, было бы нормой u параллельное их обучение и методикам устнослуховой традиции. В статье упоминаются получившие широкое распространение в мире методы: методика немецкого композитора Карла Орфа, основу которой составляет импровизационное музицирование; методика японского скрипача Шиничи Судзуки, основанная на подражании; методика безнотного обучения музыкальной Академии им. Я. Сибелиуса в Хельсинки и др.

Ключевые слова: Тува; тувинская музыка; этномузыковедение; традиционная музыкальная культура; музыкальные инструменты; теория музыки; специфика звуковой организации while the numbers of music college graduates, those who studied at conservatoires, universities, academies of culture and arts, and thus come as bearers of values lying outside of the tradition. Tuvan musical practice is experiencing an invasion of academic vocabulary and non-relevant appraisal criteria. However, Tuvan musical culture, having always been primarily oral, has developed its own acoustic structure, as well as mechanisms and methods for non-scriptory transfer of knowledge. But these vernacular methods are still insufficiently explored.

The author postulates that the system of Tuvan instrumental music organization is unique and acts as a basis for unconventional sound of musical instruments and xöömei (throat singing). Distinctive timbre and inimitable flair of the sound is achieved by original system of bourdon-overtone sound coordination.

Music is created for audial enjoyment. But musicologists (mainly in Russia) are still analyzing the notation they keep making of performed folk instrumental pieces and xöomei. Such an approach drastically narrows the entire panorama of traditional instrumental music.

A positive factor is that contemporary Tuvan musicians have mastered musical notation and are familiar with the masterpieces of global music classics. But the author suggests that a parallel training in traditional oral and audial culture will be most beneficial. Some of these worldwide recognized methods are discussed in the article, such as German composer Carl Orff's improvisationbased music; Japanese violinist Shinichi Suzuki's method based on imitation; notationless education at J. Sibelius Academy in Helsinki, etc.

Keywords: Tuva; Tuvan music; ethnomusicology; traditional music culture; musical instruments; theory of music; features of music organization

\section{Введение}

Сформировавшаяся с древнейших времен, музыкальная культура тувинцев на протяжении ряда столетий развивалась исключительно в контексте кочевого образа жизни, не претерпевая кардинальных перемен вплоть до первой половины 20-х годов XX столетия.

В середине 1920-х годов тувинская культура начала испытывать перемены, которые мы называем первым глубинным потрясением. После 1917 г. 
тувинцы, также, как и многие народы, оказались вовлечены в революционное движение, вызвавшее коренные изменения в их жизни. В период строительства социализма были внесены существенные изменения в традиционную, в том числе, и музыкальную культуру тувинцев. Идея «профессионализации» народной музыки, активно проводившаяся в жизнь с первых лет строительства социализма в Туве, сопровождалась попытками адаптации народных музыкантов к малопонятным им критериям оценок академической музыки. Результатом этого опыта явилась модификация не только традиционных музыкальных инструментов, но и всей эстетиконормативной основы традиционной музыкально-звуковой системы. В 1991 г., после распада СССР, тувинская культура испытала второе потрясение, которое случилось в течение этого же столетия.

Следовательно, в течение одного XX столетия тувинская музыкальная культура функционировала в трех разных государственных, политических и социально-экономических условиях, пережив за этот короткий исторический промежуток два глубинных потрясения.

В настоящее время, на фоне свершившихся в 90-е годы XX столетия событий, с особой остротой осознается необходимость переосмысления достижений и потерь, произошедших в музыкальной культуре Тувы. В этой связи актуальным становится назревшая необходимость научного осмысления аксиологического аспекта традиционной культуры в условиях периода ценностных кризисов и поиска новых культурных оснований и ориентиров. Эти задачи нами ставились и ранее (Сузукей, 2006, 2012), но в данном случае анализ развивается с учетом новой литературы и новых данных.

Целью данной работы является попытка рассмотрения некоторых базовых параметров тувинской музыкальной культуры, которые, несмотря на социальные иполитическиепотрясения, сохраняют системную целостность в звуковой структуре, что само по себе является новым и актуальным, так как до настоящего времени никем не ставилась такая проблематика. Актуальность темы продиктована также и существующими концептуальными расхождениями между музыкальной практикой и научным ее освоением.

В соответствии с поставленной целью основной задачей работы является раскрытие причин существующих противоречий между практикой, теорией и современной системой обучения музыкантов, грозящих, в конечном счете, привести к потере внутренних, имманентно присущих свойств тувинской музыки. 


\section{Теория, практика и культурная политика}

Общеизвестно, что научное знание формируется на основе данных практического опыта путем абстрагирования и логического анализа этих данных. Иначе говоря, теория представляет собой целостное знание о закономерностях уже существующих связей и специфических особенностей практического опыта. При этом критерием истинности и основой развития теории выступает, как известно, практика. Однако в процессе как практического, так и теоретического освоения тувинской традиционной музыкальной культуры возникла парадоксальная ситуация, когда эта аксиома (неразрывное единство теории и практики), представляющая собой фундаментальную основу гносеологии была фактически проигнорирована.

Возникновение таких противоречий было обусловлено как объективными, так и субъективными причинами. XX век вписался в ход истории человечества со своими мирового масштаба революционными коррективами, которые сметали устои традиционных, особенно кочевых, культур. Драматичность ситуации того времени усугублялась еще и тем, что революционность эпохи наложилась на европоцентристские предпочтения, определявшие в целом и методологическую направленность почти всех гуманитарных наук.

Не только практика «усовершенствования» музыкальных инструментов, но и общая установка на «профессионализацию» музыкальных культур в национальных республиках бывшего Советского Союза была инициирована идеологической установкой культурной политики государства. Унификация культуры на всей территории СССР была ориентирована исключительно на европейскую модель развития музыкального творчества без учета специфики существующих в этнических культурах практик. Одна из причин, по мнению Т. Б. Будегечи, заключалась в отсутствии знаний о культуре кочевого общества. Она писала: «Как в начале XX века не существовало и, так и в конце его не имелось целостной системы эстетических знаний об искусстве кочевников» (Будегечи, 1995: 13; курсив мой. - В. С.), в чем нельзя с ней не согласиться. «Искусство тогда было сверхидеологизированным, политика партии дружественного государства - Советского Союза - излагалась в произведениях литературы, музыки и в театре. Самая важная черта искусства тех лет - полное и слепое следование примеру “старшего брата”, исключающее поиски более приемлемых для тувинского народа форм искусства. Требовалось лишь копировать лучшие произведения русской советской культуры», - отмечает и искусствовед А. К. Кужугет (Кужугет, 2003: 201). «В советский период отечественная политика в обла- 
сти культуры была одновекторной. Будучи предельно централизованным и идеологизированным управлением, она представляла собой, прежде всего, процесс «вживления» партийно-политических императивов (главными из которых являлись принципы классовости, партийности и народности) в практику художественно-творческой деятельности и культурно-массовой работы. Подобного рода «нажим», не нуждался в обратной связи, максимально ограничивая возможности саморазвития культурной жизни по линии возрастания многообразия» (Балакшин, 2005: 3).

Основную причину многих бед социализма, например, М. П. Капустин видит в преувеличении роли насильственного революционного начала - революционизма, что привело к бесчисленным деформациям советского общества. Выход из создавшейся ситуации автор видит в возвращении политики и культуры на магистраль общечеловеческой цивилизации (Капустин, 2002).

В условиях современности в контексте активного обсуждения таких проблем, как специфика этничности, идентичности, аутентичности, становится актуальным и значимым интерес и к культурной отличительности. «Частные, этнодетерминированные моменты специфики движения социума в национальных регионах, зафиксированные наукой, могут на самом деле явиться маркерными точками реализации фундаментальных, базовых явлений и феноменов. Таким образом, глобализация, консолидация и интеграция в сфере гуманитарных наук для национальных регионов России в первую очередь должны означать, - как справедливо отмечает М.Улаков, - не трансформацию национально-специфического знания в направлении всеобщей стандартизации и нивелировки методов и моделей научного поиска, как было при советской власти. А, скорее наоборот - продвижение и развитие в новой научно-информационной среде тех аналитических систем, которые основаны на необычности исследуемого материала» (Улаков, 2004: 4; курсив мой. - В. С.).

Таким образом, теория, практика и культурная политика - три составляющие, которые по природе своей должны быть взаимоувязанными. Но в случае с традиционными культурами они оказались не согласованными.

В настоящее время все ощутимее становится неизбежное численное уменьшение носителей традиционной культуры устно-слухового типа в связи с их естественным уходом из жизни, и по этой причине происходит ослабление влияния и снижение их роли в культуре. Современное пожилое население республики - это поколение строителей социалистического общества, с детских лет усвоившие идеалы той эпохи. Наблюдается и за- 
метное увеличение числа выпускников музыкальных школ, училищ, консерваторий и университетов, академий культуры и искусств, воспитанных не на традиционных ценностных ориентирах. Эта количественно увеличивающаяся масса дипломированных специалистов начинает активно внедрять академическую терминологию и привносить в тувинскую музыкальную практику не свойственные традиционной музыке критерии оценок и термины. Это в той ситуации, когда по тувинской традиционной музыкальной культуре существует уже достаточное количество серьезных научных трудов как отечественных, так и зарубежных ученых (Аксенов, 1964; Богданов, 1981; Бюрбээ, 1964; Чернов, Маслов, Дмитриев, 1992; Казанцева, 2002, 2003; Кыргыс, 1992, 2002; Мелодии хоомея ... , 1994; Осипенко, 1994; Сузукей, 2007; Карелина, 2009; Gunji, 1980; Bloothooft et al., 1992; Levin, Suzukei, 2006; Tongeren, 2002 и др., а также: Рукописный фонд ТИГИ. Д. 864. Выписки материалов по фольклору, языкознанию и истории Тувы, хранящиеся в фондах Томского гос. университета и Томского областного краеведческого музея. Архив А. В. Анохина).

Тем не менее, результаты научных исследований пока что остаются не задействованными в системе образования при разработке учебных программ, учебно-методических пособий, используемых для обучения музыкантов-народников. В учебных заведениях культуры и искусств Тувы продолжают действовать государственные образовательные стандарты, ориентированные исключительно на требования и нормы европейской классической музыки, введенные еще в советское время. Также и на отделениях народных (национальных) инструментов продолжается обучение студентов на «усовершенствованных» (по аналогии с инструментами Русского оркестра В. В. Андреева) национальных инструментах.

А традиционная культура, будучи принципиально устной, в процессе своего становления и развития выработала свою систему звукового строя и также механизмы и методы безнотной, т. е. бесписьменной передачи знаний, которые являются очень эффективными в смысле быстроты обучения начинающих. К сожалению, эти народные методы до сих пор остаются малоизученными.

\section{Специфика звуковой структуры тувинской инструментальной музыки}

Музыкальная фольклористика, отпочковавшись, как дочерняя ветвь, от академического музыковедения, при изучении традиционных музыкальных культур, особенно на начальном этапе своего становления, активно 
задействовала исследовательские методы, выработанные в европейском теоретическом музыкознании, и терминологический аппарат. Например, такие термины, как лад, тональность, звукоряд, дорийский или лидийский лад, тетрахорд, пентахорд и т. д. С априорностью слуховой и теоретической установки музыкантов, имеющих базовое академическое образование, также тесно связана и острота многих проблем.

Такой, например, широко применяемый в музыкальной фольклористике метод, как анализ исследуемого материала на основе его нотной расшифровки, не всегда дает плодотворный результат. Этот метод, на наш взгляд, можно довольно успешно применять для анализа образцов лишь традиционной вокальной музыки тувинцев, поскольку она реализуется за счет высотного чередования звуков. И такой способ музицирования называется звуковысотной, поскольку создание музыки происходит за счет чередования высоты разных звуков. Звуковысотная организация составляет фундаментальную основу теоретической концепции равномернотемперированного строя (гомофонно-гармонической системы), которая сформировалась в процессе исторического становления и развития европейской академической музыки.

А система организации тувинской инструментальной музыки довольно специфична, и выступает той основой, которая придает необычность звучанию музыкальных инструментов и хоомея (горлового пения), привлекая к ним всеобщее внимание во всем мире. Характерный тембр и неповторимый колорит их звучания обеспечивается своеобразной системой бурдонно-обертоновых звуковых соотношений, за которой стоит особая логика звукового мышления (Аксенов, 1964; Gunji, 1980; Чернов, Маслов, Дмитриев, 1992; Сузукей, 1989, 2006, 2007).

Хоомей функционирует в единой с музыкальными инструментами системе звуковых координат, неоспоримым признаком общности которых выступает бурдонно-обертоновая структура звуковой организации. Поэтому определение этого вида искусства как «пение» весьма спорно и с таким его обозначением, как «горловое пение» можно согласиться лишь в силу привычности и широты его использования. В данном контексте хоомей рассматривается нами как инструментальное искусство, поскольку с точки зрения специфики звуковой организации хоомей несомненно стоит в одном ряду с инструментальным творчеством (Сузукей, 1993, 2006; Tongeren, 2002; Levin, Suzukei, 2006).

Эстетико-нормативные представления тувинского народа о музыкаль- 
ном звуке как о наименьшем структурном элементе, как о «строительном» материале инструментальной музыки, имеет существенное отличие от того, которое характерно для европейской музыкальной теории, изначально опирающейся на материал необертоновых мелодических культур. Имеется в виду принципиальная разница, заключающаяся в том, что мелодии инструментальной музыки тувинцев строятся только из обертонов, в то время как в академической музыке использование обертонов в мелодии является специфическим приемом, применяющимся лишь эпизодически. К тому же отличаются способы их извлечения на музыкальных инструментах и, самое главное, при этом основной тон, из которого извлекается обертон, в академической музыке не слышен.

Самым главным отличием и обязательным условием функционирования тувинской инструментальной музыки и хоомея является постоянное присутствие основного тона - бурдона. Без этого основного тона обертоновые звуки не жизнеспособны, поскольку это не самостоятельные звуковые единицы. Обязательное присутствие бурдона на фоне освобожденных обертонов (часть из которых участвует в образовании мелодии) - это самый существенный, и к тому же самый трудноулавливаемый для многих музыковедов и музыкантов момент.

Неспособность восприятия звукового явления, имеющего значительное отличие от академической системы звукообразования, негибкость в восприятии нестандартного, присутствующая при беседах со многими музыкантами и музыковедами, была отчетливо сформулирована Е. К. Карелиной следующим образом: «Специфику звуковой организации тувинской музыки, максимально выраженную в звучании струнных инструментов и горлового пения, В. Сузукей определяет как бурдонно-обертоновый комплекс. Данный термин неудачен по той же причине, что и все иноземные эквиваленты слова хоомей, поскольку вызывает нелепый вопрос: неужели бурдон - только свойство тувинской музыки и может ли музыка вообще быть без обертонов?» (Карелина, 2009: 91). Именно такой нелепый вопрос и является ярким свидетельством априорности слуховой и теоретической установки музыкантов, имеющих базовое академическое образование.

Бурдон (остинатный звук или опорный тон) и обертоны тувинской музыки впервые наиболее подробно были описаны еще А. Н. Аксеновым (Аксенов, 1964). Во всех, изданных позже работах по тувинской музыке, как музыковедов, так и физиков-акустиков используются именно (и только) эти термины - бурдон и обертоны. Поэтому это определение, по сути, не 
является изобретением автора. Мы лишь сводим эти термины воедино, и говорим только о специфическом единстве этих явлений в тувинской инструментальной музыке.

Понятно, что звуки, которые состоят из обертонов - это и есть «строительный материал» музыки в принципе. Вопрос-то состоит только в том, как этот «строительный материал» скомпонован в разных культурах. Об отличии в извлечении обертонов в разных культурах и говорится во всех наших работах. Автор никогда ни устно, ни письменно не отрицала наличия бурдона и обертонов в других музыкальных культурах и нигде не говорит о том, что «бурдон - только свойство тувинской музыки».

Речь идет только о том, что именно неразрывное единство бурдоннообертоновой организации звукового материалатрадиционной инструментальной музыки тувинцев является самым ярким внешним проявлением реально функционирующей музыкальной системы, имеющей специфические закономерности внутренней организации.

Для носителей традиционной культуры, особенно для народных исполнителей, изъятие бурдона из звуковой фактуры инструментальной музыки создало ярко выраженное ощущение дискомфорта, причину которого им самим было очень трудно сформулировать вербально. По этой причине в 1960-1970-х годах усовершенствованные варианты народных инструментов отвергались носителями традиции лишь с лаконичной оценкой: «Это звучит не по-тувински». В то время было не совсем понятно, что означает такое высказывание, как «звучит не по-тувински».

\section{Проблемы, возникающие при попытках теоретического освоения бурдонно-обертоновой инструментальной музыки}

Существующая практика анализа бурдонно-обертоновой музыки по нотным расшифровкам является априорно привнесенным методом анализа европейской музыки, где обертоны не используются так широко и повсеместно, как в тувинской инструментальной музыке. Обертоны в мелодии академической музыки появляются очень редко лишь как способ украшения мелодии. К тому же обертоновые и не обертоновые звуки это разные по природе звуковые явления. Обертоны - это не самостоятельные звуковые единицы. В тувинской инструментальной музыке они реально слышимы только в том случае, когда есть бурдон, из которого они извлекаются. Можно сказать, что обертоновая мелодия в тувинской инструментальной традиции - это виртуальная реальность. Если убрать 
бурдон, то тут же исчезнут и все обертоны, которые не имеют собственного источника звука.

Разные по природе явления не могут анализироваться одними и теми же методами. Универсальных методов для изучения принципиально разных явлений не может быть. Ведь известно, что метод, как и термин, являются отражением имманентных свойств того материала, на котором они сформулированы и выработаны. Тем не менее, до сих пор среди музыковедов существует и такая типичная позиция, как высказанная Е. К. Карелиной: «Как можно отречься от азов музыки, впитанных с детства? Как можно отрицать универсальное, принятое во всем мире значение европейской школы теории музыки?» (Карелина, 2004: 4). Между тем никто не пытается отрицать значение европейской школы теории музыки. Мало того, попытки объяснения причин несоответствия некоторых музыковедческих терминов специфике традиционной музыки, однобоко трактуется как стремление отрицания и неприятия достоинств европейской классической музыки, что в принципе не соответствует реальности.

Система нотной записи - это двухмерная графика, условно отображающая записанную музыку по высоте и по длительности звучания, т. е. где отображена звуковысотная система. Однако, система бурдонно-обертоновой звуковой организации, в которой изначально заложена стереофоничность звучания, по идее должна отображаться при помощи многомерной графики, которая пока еще не создана.

Однако, на наш взгляд, задача графического отображения данной музыки - это не есть основная цель исследований. Музыка создается не для зрительного восприятия, как изобразительное искусство, а она, прежде всего, является творением, предназначенным только и именно для слухового восприятия. Но, как ни странно, для методов акустики и музыкально-фольклористических исследований всегда характерно стремление зафиксировать музыку в какомнибудь статичном варианте в виде нотного изображения, либо в виде акустических спектрограмм. И дальнейшая работа исследователей по анализу зафиксированных материалов проходит уже без участия самих исполнителей. Такие исследования также, возможно, и нужны.

Но, необходимо учесть следующий момент. В каждой культуре есть постоянные и переменные величины. Ценные достижения культуры передаются последующим поколениям, скорее всего, через наиболее стабильные, постоянные величины, на которые опирается культура в своем дальнейшем развитии. 
В европейской композиторской музыке постоянство выражается в том, что никогда не меняется текст, написанный композитором, т. е. никогда не меняется высотное положение звуков, задействованных в конкретном произведении. Никто не имеет права вносить изменения в авторский текст. Во время исполнения произведения появление не вписанных в произведение звуков и отклонения от темпа и размера резко осуждается как незнание текста. Поэтому нотный текст является надежным, достоверным документом, сохраняющим постоянство звуковысотных характеристик произведения. Постоянство и стабильность высотных характеристик звуков позволяет анализировать произведение лишь по нотному тексту даже в тиши кабинета. Все теоретические постулаты академического теоретического музыкознания с его аналитическим аппаратом изначально были сформулированы на этом незыблемом фундаменте.

Но в традиционной инструментальной музыке тувинцев звуковысотная характеристика исполняемой музыки является переменной величиной. Дело в том, что сколько бы раз ни исполнял музыкант одно произведение, столько и разных вариантов будет фиксировать музыковед на аудио- и видеозаписях. Это означает, что для самих носителей традиционной культуры звуковысотная характеристика не имеет значения константной величины, имеющей статус фундаментальной опоры для самой культуры. В традиционной культуре есть свои стабильные ориентиры и механизмы передачи знаний последующим поколениям. Одной из важнейших задач научного исследования должен стать поиск постоянных величин, которые играют роль «несущих конструкций» традиционной культуры. И в этом огромную роль играет мнение самих носителей традиционной культуры и то, что они сами считают наиболее важным в исполняемой ими музыке.

Но до сих пор музыковеды продолжают использовать аналитические методы, опирающиеся на другие значения константности. Они анализируют нотированные варианты записанных ими исполнений народной инструментальной музыки и хоомея. Такой исследовательский метод, в основном, характерен для российских исследователей, как наследие, доставшееся им от советской музыкальной фольклористики. Такой подход ограничивает всю панораму традиционной инструментальной музыки до ее единичных образцов. На основе такого анализа они описывают свои выводы в терминах европейского музыкознания. И, как правило, эти выводы для традиционных музыкантов остаются ни о чем им не говорящими, малопонятными или совсем непонятными сентенциями и почти никогда не имеют выхода на практику. 


\section{Бурдонно-обертоновая система как источнк тембрового богатства звучания инструментальной музыки и хоомея}

Логика звукового мышления тувинцев, изначально ориентированная на бурдонно-обертоновое интонирование, четко прослеживается в заданности определенных параметров народных инструментов. Эти параметры реализовывались в таком их фоническом комплексе, как богатство и глубина темброрегистрового звучания, которое обеспечивалоь широким спектром обертонов. Именно тембровое богатство звуковой системы позволял исполнителям быть непревзойденными мастерами звукоподражаний, исполняемых как на музыкальных инструментах, так и в разновидностях горлового пения. Примеров можно приводить бесконечное множество. Например, даг каргыраазы (горный каргыраа), хову каргыpaазы (степной каргыраа), эзенгилээр (подражание звону стремян), борбаннадыр (подражание перекатывающимся круглым звукам), киштедир (подражание ржанию лошади) и т. д. Тембр, например, одного из любимого тувинцами инструмента - игила характеризуется сочной, бархатной, иногда гнусавой, тёплой звучностью, с налётом некоторой сентиментальности, а отсюда как бы с приглушенной страстностью (узун-хоюг, уянныг, уяңгылыг, уяранчыг). Особо лестную характеристику тувинцы дают инструментам, по тембру близким к человеческому голосу, особенно к низким и средним по диапазону женским голосам.

Своеобразие тембра игила заключено и в особенности звукоизвлечения, основанного на флажолетном принципе: т. е. две струны никогда не прижимаются к шейке инструмента, а к ним лишь слегка прикасаются подушечками пальцев, вызывая мягкий, тёплый (определения народных исполнителей) звук, играют как бы поглаживая струны, прием который по-тувински называется «суйбап ойнаар». Народные исполнители также широко применяют прием вибрато, которое придает особую теплоту и приближенность к человеческому голосу. Недаром некоторые знаменитые исполнители уникального искусства тувинцев - горлового пения (КараСал Ак-оол, Кайгал-оол Ховалыг, Куулар Эрес-оол и другие) предпочитают сопровождение на игиле.

Игил у тувинцев по своим техническим возможностям, по своей мягкости, гибкости, легкости звука и способности передавать множество оттенков эмоций, справедливо считается народными музыкантами несравненным выразителем нежности, грусти, страсти и истолкователем лирико-созерцательного, драматического, комического и трагического содержания. Кроме того, у тувинцев лучшими исполнителями считались те, у 
кого инструмент «говорил» - «чугааладып ойнаары». Благодаря столь богатым техническим и выразительным возможностям игил является сольным «концертным» инструментом, обладающим обширным репертуаром.

Одним из главных лейтмотивов инструментальной музыки тувинцев является природа. По характеру своего скотоводческого труда тувинец много времени проводил на открытом воздухе, близко соприкасаясь со множеством оттенков звуков живой и неживой природы. Осознание человеком своей неразрывной связи с окружающей его природой является одной из социально значимых платформ идеологии шаманского культа, в котором был сакрализован механизм управления повседневной жизнью народа. Причем, механизм этот также основывался на анимистических представлениях, связанных с обожествлением природы, почитанием животного мира и грозных сил природы (грома, молнии, урагана и т. п.).

Мифологический комплекс космогонических представлений кочевников отражает структуру сотворенного кочевником мира сакрального космоса, и позволяет понять незыблемость его ощущения нерасторжимой связи с природой. Этот сложившийся в давнюю пору, эстетический идеал, образ нераздельности человека и природы, выступает фундаментальной основой мировоззрения кочевников.

Этим обстоятельством объясняется и то, что центральное место в художественном творчестве тувинцев занимает образ природы. Воспевание картины окружающей природы - это не результат праздного созериания, а одно из социальных проявлений идеологии шаманизма, обусловленных специфическим восприятием обожествляемой природы.

В музыке тувинцев, особенно в инструментальной, значительное место отводится воспеванию родной природы. Исполнение, например, на смычковом инструменте игиле «Узун хоюг» Кара-Салом Ак-оолом для носителей традиционной культуры четко ассоциируется с образом Тувы во всей красоте ее степных просторов, величественности тайги, чистейшей голубизны рек и озер, пронзительной синевы неба над головой и щедрого солнца, встающего над Саянскими хребтами. Тончайшая образность - вот характерная особенность тувинского инструментального исполнительства, в котором с особой силой звучит жизнеутверждающее гуманистическое начало. В репертуаре хомуса (варгана) и смычкового игила имеются также импровизации, именуемые «Хову аялгазы» - «Мелодии степи» (или «Степные мелодии») и в горловом пении существует стиль «Хову каргыраазы» - «Степное каргыраа» или «Даг каргыраазы» - «Горный каргыраа», в 
которых нет прямых, натуралистических звукоподражаний. Тем не менее, эти импровизации полны образной выразительности, создающей своеобразный степной или горный колорит. «Большая часть традиционных песен жанра ырлар имеет лирико-созерцательный характер; основной, обобщающий и поэтический образ этих песен - образ родного края, - пишет и А. Н. Аксенов, - В них любовно воспевается “великая река” Енисей, высокогорная тайга, долины, утесы, реки, озера. Эти образы ассоциируются то с кочевьями, то с мыслью о любимой, то с воспоминаниями об охоте, то с мыслью о верном друге - коне, постоянном спутнике, называемом в песнях множеством нежных имен» (Аксенов, 1964: 28).

Чуткое слуховое восприятие звуков окружающей природы, специфика звукошумового и зрительного восприятия окружающей природы наложило существенный отпечаток на логику звукового мышления тувинцев. В инструментальной музыке именно объемность, многократность, пространственность звукового потока придает тот тонкий тембровый колорит, присущий выразительному языку тувинской народной музыки, позволяющему художественно чутко познавать реальность. При этом создается голографический, а не фотографический, образ родной природы. И именно необычное комплексное звучание инструментальной музыки, ее темброрегистровая характеристика является существенным, смыслонесущим компонентом, воплощением образа в звуке, познанием мира в звуках. Одна из причин возникновения проблем при изучении специфического музыкального материала заключается, также, в малоразработанности категории «тембра» в теоретическом музыкознании.

Кроме того, необходимо учитывать, что за конкретными исследовательскими методами, лежащими на поверхности, стоят глубинные причины мировоззренческого характера. Традиционные представления кочевников о макрокосмосе и микрокосмосе выступает важнейшей основой, определяющей место человека в объективной действительности и его отношение к этой действительности и к самому себе, как к частице этой действительности, прямо противоположной от христианского миропонимания, где человек противопоставлен природе, где человек и природа - это две противоборствующие силы (Фейербах, 1955: 183), где человек позиционируется как «царь природы».

На современном этапе, когда процесс обучения традиционной музыке и народным инструментам в учебных заведениях продолжается по той же методике, которая была заложена в советское время, то проблема сохранения и дальнейшего развития традиционной музыки будет весьма 
проблематичной. Одним из ярких примеров нивелировки мы наблюдаем в таком ярком жанре тувинской музыки, как хоомей. Дело в том, что хоомейжи старшего поколения, например, Ак-оол Кара-Сал, Хунаштаар-оол Ооржак, Максим Дакпай, Санчы Кызыл-оол и другие, в своем творчестве были абсолютно не похожи друг на друга и слушатели их никогда не путали даже без объявления имени исполнителя. А нынешнее поколение молодых музыкантов стремительно начинают терять свою исполнительскую индивидуальность. А это одна из характерных свойств традиционной музыкальной культуры, где каждый музыкант всегда был представлен яркой индивидуальностью. А обучение по нотам народным инструментам произведений, предусмотренных учебной программой, практически начисто «вымывает» импровизационную сущность традиции инструментального исполнительства.

Кстати, необходимо отметить, что в современном мире давно уже получили широкое распространение такие методы, как методика немецкого композитора Карла Орфа, основу которой составляет импровизационное музицирование (Методика Карла Орфа, Электр. ресурс).

Автором другой популярной методики безнотного обучения является методика японского скрипача Шиничи Судзуки, основанная на подражании. Ведь 95\% людей так никогда и не могут научиться правильно петь только потому, что им с детства внушали: копировать - это плохо. Их лишали главного инструмента обучения - подражания. Он создал методику, которая в наши дни распространилась по всему миру, и нашла десятки тысяч последователей и учеников, многие из которых стали первоклассными музыкантами. Мир был поражён его удивительными ансамблями 4-5 летних скрипачей из 100-200 детей, чистенько и синхронно исполнявших музыку Вивальди, Моцарта, Бетховена (Как обучать детей музыке ..., 2013: Электр. ресурс).

Исходной позицией концепции венгерского композитора и педагога 3.Кодая стало убеждение в том, что основой музыкальной культуры нации, a, следовательно, и музыкального воспитания, должна стать народная музыка. Чтобы облегчить, и ускорить процесс развития слуха, педагог разработал метод относительной сольмизации и использования ручных знаков. Главными особенностями данной методики является сочетание певческой деятельности с разнообразными движениями, хлопками в ладоши, ритмичным аккомпанементом, играми и т. д. (Кодай, 1961) 
С конца 1970-х годов и в музыкальной Академии им. Я. Сибелиуса в Хельсинки (http://www.uniarts.fi/) также была введена методика безнотного обучения, продуктивность которой нам посчастливилось наблюдать во время мастер-классов, проведенных педагогами данной Академии во время конференции в 2009 г.

С другой стороны, естественно положительным является и то, что современные тувинские музыканты владеют нотной грамотой, и приобщаются к шедеврам мировой музыкальной классики. Тем не менее, было бы нормой и параллельное их обучение и методикам устно-слуховой традиции.

\section{Заключение}

Начиная с 90-х годов прошлого столетия, тувинская музыка начала привлекать к себе пристальное внимание мировой общественности. Кроме того, она стала востребованной и на многих концертных площадках мира. В связи с этим был инициирован и научный интерес зарубежных ученых к тувинской музыке и особенно к хоомею. Было защищено уже несколько диссертаций, опубликованы статьи и монографии. Однако общей и преобладающей чертой всех этих работ все-таки остается описательный момент феномена тувинской музыки с точки зрения разных исследователей и их научных школ. Это, видимо, естественный процесс, поскольку это был определенный этап начального знакомства с таким феноменом в сфере человеческого звукотворчества. На уровне практического освоения образцов тувинской музыки многие исполнители из разных стран уже успели овладеть механизмом извлечения специфических звукосочетаний. Другим вопросом является то, как они все по-разному интерпретируют эти звуки в собственном исполнительском творчестве и в контексте собственных культурных традиций.

Дальнейшее научное изучение и практическое освоение тувинской традиционной музыки, думается, будет максимально углубляться, и учитывать весь эмпирический (как мировоззренческий, так и практический) опыт ее создателей, т. е. наших предков, оставивших нам такие шедевры в сфере музыкального творчества. 


\section{СПИСОК ЛИТЕРАТУРЫ}

Аксенов, А. Н. (1964) Тувинская народная музыка. М.: Музыка. 255 с.

Балакшин, А. С. (2005) Культурная политика: теория и методология исследования : дисс. ... д-ра филос. Н. Нижний Новгород. 355 с.

Богданов, И. А. (1981) Комментарии к комплекту грампластинок «Тувинский фольклор». М. : Всесоюзная фирма «Мелодия».

Будегечи, Т. Б. (1995) Художественное наследие тувинцев. М. : б/и. 151 с.

Бюрбээ, С. М. (1964) Музыкальный фольклор тувинцев // Ученые записки ТНИИЯЛИ. Вып. ХІ. Кызыл. С. 62-65.

Казанцева, 3. К. (2003) А. Б. Чыргал-оол: жизнь и творчество. Кызыл: ТувИКОПР СО РАН. 188 с.

Казанцева, 3. К. (2002) Рожденный петь. К 80-летию со дня рождения Р.Д.Кенденбиля. Кызыл : Респ. типография. 104 с.

Как обучать детей музыке : три методики (2013) [Электронный ресурс] // Letidor. 1 октября. URL: https://letidor.ru/obrazovanie/a234-kak-obuchatdetey-muzyke-tri-metodiki-8757.shtml (дата обращения: 12.03.2017).

Капустин, М. П. (2002) Культура и власть. М. : Издательство Ипполитова. 427 c.

Карелина, Е. К. (2009) История тувинской музыки от падения династии Цин до наших дней. М. : Композитор. 552 с.

Карелина, Е. К. (2004) «Услышать музыку степей...» // Тувинская правда. № 5 (15816). 15 января. С. 4.

Кодай, 3. (1961) Венгерская народная музыка. Будапешт : Изд-во Корвина. 186 с.

Кужугет, А. К. (2003) Культура и искусство ТНР // Ученые записки ТИГИ. Вып. ХХ. Кызыл. 354 с. С. 193-214.

Кыргыс, 3. К. (1992) Песенная культура тувинского народа. Кызыл : Тувинское книжное издательство. 128 с.

Кыргыс, 3. К. (2002) Тувинское горловое пение. Новосибирск: Наука. 236 с.

Мелодии хоомея (1994): материалы I Междунар. музыковедческого симпозиума «Хоомей-92» (г. Кызыл, 19-23 июня 1992 г.) / отв. ред. Ю. Л. Аранчын. Кызыл : Тувинское книжное изд-во. 112 с.

Методика Карла Орфа [Электронный ресурс] // Центр раннего развития «Маленькая страна». URL: http://ministrana.ru/metodiki-rannego-razvitija/ metodika-karla-orfa/ (дата обращения: 12.03.2017). 
Осипенко, Г. А. (1994) Тувинская музыкальная литература (рукопись).

Сузукей, В. Ю. (2007) Музыкальная культура Тувы в ХХ столетии. М. : Издательский Дом «Композитор». 408 с.

Сузукей, В. Ю. (1989) Тувинские традиционные музыкальные инструменты. Кызыл : Тувинское книжное издательство. 144 с.

Сузукей, В. Ю. (1993) Бурдонно-обертоновая основа традиционного инструментального музицирования тувинцев. Кызыл : Тувинское книжное издательство. 96 с.

Сузукей, В. Ю. (2006) Конфигурация развития музыкальной культуры Тувы: динамика аксиологического аспекта. Кемерово : б/и. 207 с.

Сузукей, В. Ю. (2006) Культурно-исторические корни музыкального наследия тувинцев: функционирование и модернизация в XX веке : дисс.... д-ра культ. Кемерово. 326 с.

Сузукей, В. Ю. (2012) Проблема теоретического и практического изучения и преподавания традиционной музыки Тувы // Сибирский педагогический журнал. № 1. С. 233-239.

Улаков, М. 3. (2004) Новые тенденции развития региональных тюркологических исследований // Российская тюркология. № 2. С. 3-9.

Фейербах, Л. (1955) Избранные философские произведения : в 2 т. М. : Госполитиздат. Т. 2.285 с.

Чернов, Б. П., Маслов, В. Т., Дмитриев, Л. Б. (1992) Тайна тувинского «дуэта», или свойство гортани человека формировать механизм аэродинамического свиста. Новосибирск : б/и. 86 с.

Bloothooft, G., Bringmann, E., van Cappellen, M., van Luipen, J. B., Thomassen, K. P. (1992) Acoustics and perception of overtone singing // Journal of the Acoustical Society of America. Oct;92(4 Pt 1): 1827-1836.

Gunji, S. (1980) An Acoustical Consideration of Xoomij // Musical Voices of Asia. The Japan Foundation, Heibonsha Ltd, Tokyo. P. 135-141.

Levin, T., Suzukei, V. (2006) Where Rivers and Mountains Sing: sound, music and nomadism in Tuva and beyond. Indiana University Press. 281 p.

Tongeren van, M. C. (2002) Overtone Singing. Physics and Metaphysics of Harmonics in East and West. Amsterdam. 271 p. 


\section{REFERENCES}

Aksenov, A.N. (1964) Tuvinskaia narodnaia muzyka [Tuvan folk music]. Moscow, Muzyka. 255 p. (In Russ.).

Balakshin, A. S. (2005) Kul'turnaia politika: teoriia i metodologiia issledovaniia [Cultural policy: theory and research methodology] : Diss.... Doctor of Philosophy. Nizhnii Novgorod. 355 p. (In Russ.).

Bogdanov, I. A. (1981) Kommentarii k komplektu gramplastinok «Tuvinskii fol'klor» [Comments for set of records «Tuvan folklore»]. Moscow, Melodiia. (In Russ.).

Budegechi, T. B. (1995) Khudozhestvennoe nasledie tuvintsev [The artistic heritage of Tuvans]. Moscow. 151 p. (In Russ.).

Biurbee, S.M.(1964) Muzykal'nyi fol'klor tuvintsev [Musical folklore of Tuvans]. Uchenye zapiski TNIIIaLI, vol. XI. Kyzyl. Pp. 62-65. (In Russ.).

Kazantseva, Z. K. (2003) A. B. Chyrgal-ool: zhizn' i tvorchestvo [A. B. Chyrgal-ool: the life and work]. Kyzyl, TuvIKOPR SO RAN. 188 p. (In Russ.).

Kazantseva, Z. K. (2002) Rozhdennyi pet'. K 80-letiiu so dnia rozhdeniia R.D.Kendenbilia [Born to sing. To the 80th anniversary of R. D. Kendenbil]. Kyzyl, Resp. tipografiia. 104 p. (In Russ.).

Kak obuchat' detei muzyke : tri metodiki (2013). Letidor, 1 October [online]: https://letidor.ru/obrazovanie/a234-kak-obuchat-detey-muzyke-tri-metodiki8757.shtml (access date: 12.03.2017). (In Russ.).

Kapustin, M. P. (2002) Kul'tura i vlast' [Culture and power]. Moscow, Ippolitov Publ. 427 p. (In Russ.).

Karelina, E. K. (2009) Istoriia tuvinskoi muzyki ot padeniia dinastii Tsin do nashikh dnei [The history of Tuvan music from the fall of the Qing dynasty to the present day]. Moscow, Kompozitor. 552 p. (In Russ.).

Karelina, E. K. (2004) «Uslyshat' muzyku stepei...». Tuvinskaia Pravda, no. 5 (15816), 15 January, p. 4. (In Russ.).

Kodaly, Z. (1961) Vengerskaia narodnaia muzyka [Hungarian folk music]. Budapesht, Korvin Publ. 186 p. (In Russ.).

Kuzhuget, A. K. (2003) Kul'tura i iskusstvo TNR. Uchenye zapiski TIGI, vol. XX. Kyzyl. 354 p. Pp. 193-214. (In Russ.).

Kyrgys, Z. K. (1992) Pesennaia kul'tura tuvinskogo naroda [Song culture of the Tuvan people]. Kyzyl, Tuvinskoe knizhnoe izdatel'stvo. 128 p. (In Russ.). 
Kyrgys, Z. K. (2002) Tuvinskoe gorlovoe penie [Tuvan throat singing]. Novosibirsk, Nauka. 236 p. (In Russ.).

Melodii khoomeia (1994): materialy I Mezhdunar. muzykovedcheskogo simpoziuma «Khoomei-92» (g. Kyzyl, 19-23 iiunia 1992 g.), ed. by Iu. L. Aranchyn. Kyzyl, Tuvinskoe knizhnoe izd-vo. 112 p. (In Russ.).

Metodika Karla Orfa. Tsentr rannego razvitiia «Malen'kaia strana» [online] Availablae at: http://ministrana.ru/metodiki-rannego-razvitija/metodika-karlaorfa/ (access date: 12.03.2017). (In Russ.).

Osipenko,G.A.(1994) Tuvinskaia muzykal'naia literatura[Tuvan musicliterature] (manuscript). (In Russ.).

Suzukei,V.Iu.(2007) Muzykal'naia kul'tura TuvyvXX stoletii [The musical culture of Tuva in 20th century]. Moscow, Kompozitor Publ. Haus. 408 p. (In Russ.).

Suzukei, V. Iu. (1989) Tuvinskie traditsionnye muzykal'nye instrumenty [Tuvan traditional musical instruments]. Kyzyl, Tuvinskoe knizhnoe izdatel'stvo. 144 p. (In Russ.).

Suzukei, V. Iu. (1993) Burdonno-obertonovaia osnova traditsionnogo instrumental'nogomuzitsirovaniiatuvintsev[Bourdonne-overtonebasis oftraditional instrumental music of Tuvans]. Kyzyl, Tuvinskoe knizhnoe izdatel'stvo. 96 p. (In Russ.).

Suzukei,V. Iu.(2006) Konfiguratsiia razvitiia muzykal'noi kul'tury Tuvy: dinamika aksiologicheskogo aspekta [The configuration of the development of musical culture of Tuva: the dynamics of axiological aspect]. Kemerovo. 207 p. (In Russ.).

Suzukei, V. Iu. (2006) Kul'turno-istoricheskie korni muzykal'nogo naslediia tuvintsev: funktsionirovanie $i$ modernizatsiia $v X X$ veke : Diss. ... Doctor of Culturology. Kemerovo. 326 p. (In Russ.).

Suzukei, V. Iu. (2012) Problema teoreticheskogo i prakticheskogo izucheniia i prepodavaniia traditsionnoi muzyki Tuvy. Sibirskii pedagogicheskii zhurnal, no. 1, pp. 233-239. (In Russ.).

Ulakov,M.Z.(2004) Novyetendentsiirazvitiia regional'nykh tiurkologicheskikh issledovanii. Rossiiskaia tiurkologiia, no. 2, pp. 3-9. (In Russ.).

Feuerbach, L. (1955) Izbrannye filosofskie proizvedeniia [Selected philosophical works]: in 2 vol. Moscow, Gospolitizdat. Vol. 2. 285 p. (In Russ.).

Chernov, B. P., Maslov, V. T. and Dmitriev, L. B. (1992) Taina tuvinskogo «dueta», ili svoistvo gortani cheloveka formirovat' mekhanizm aerodinamicheskogo svista. Novosibirsk. 86 p. (In Russ.). 
Bloothooft, G., Bringmann, E., van Cappellen, M., van Luipen, J. B., Thomassen, K. P. (1992) Acoustics and perception of overtone singing. Journal of the Acoustical Society of America, Oct., no. 92(4 Pt 1), pp. 1827-1836.

Gunji, S. (1980) An Acoustical Consideration of Xoomij. Musical Voices of Asia. The Japan Foundation, Heibonsha Ltd, Tokyo. P. 135-141.

Levin, T. and Suzukei, V. (2006) Where Rivers and Mountains Sing: sound, music and nomadism in Tuva and beyond. Indiana University Press. $281 \mathrm{p}$.

Tongeren, M. C. (2002) Overtone Singing. Physics and Metaphysics of Harmonics in East and West. Amsterdam. 271 p.

Submission date: 16.04 .2017$.

\section{Для цзитирования:}

СузукейВ.Ю.Проблемы научного изучения и практического освоения тувинской музыки (на примере тувинского инструментального искусства) [Электронный ресурс] // Новые исследования Тувы. 2017. № 2. URL: https://nit.tuva.asia/nit/article/view/705 (дата обращения:...). DOI: 10.25178/nit.2017.2.1

\section{For citation:}

Suzukey V. Yu. Issues of academic study and practical acquisition of Tuvan music (a case study of Tuvan instrumental music). The New Research of Tuva, 2017, no. 2 [online] Available at: https://nit.tuva.asia/nit/article/view/705 (access date:...). DOI: 10.25178/nit.2017.2.1 